\title{
Erișkin gömük penis rekonstrüksiyonunda yeni suprapubik insizyon tekniği
}

\section{A new suprapubic incision technique for reconstruction of the adult buried penis}

\author{
Hasan Yılmaz', Murat Üstüner², Mustafa Yüksekkaya', Mehmet Esat Kösem¹, Ali Kemal Uslubaș¹, \\ Mustafa Melih Çulha ${ }^{1}$
}

\section{öz}

AMAÇ: Çalışmamızda, erişkin gömük penis hastalarında suprapubik lipektomi sonrası penisin daha uzun ve estetik görünmesi için uyguladığımız suprapubik insizyon tekniğini değerlendirmeyi amaçladık.

GEREÇ VE YÖNTEM: Kliniğimizde 2013-2016 yılları arasında, suprapubik yağlanma nedeniyle fonksiyonel penis boyunun kısaldığını düşünen 19 hastanın verileri geriye dönük değerlendirildi. Penopubik bileşkenin yaklaşık $2 \mathrm{~cm}$ üstünden ters hilal şeklinde $8 \mathrm{~cm}$ 'lik transvers cilt insizyonu yapıldıktan sonra, penis kökü, rektus fasyası ve cilt arasındaki tüm adipoz dokular eksize edildi (suprapubik lipektomi). Ardından, insizyonun lateral uçları subdermislerinden orta hatta rektus fasyasına $2 / 0$ emilebilir poliglaktin sütürler ile sabitlendi. Böylece transvers insizyon vertikal plana getirilmiş oldu. Vertikal planda alt ve üst uçta oluşan cilt kulakçıkları açık üçgen şeklinde eksize edilerek, insizyonun estetik görünümün sağlanması amaçlandı. Daha sonra insizyon kapatıldı. Suprapubik lipektomi ile elde edilen penis uzunluğunun korunması ve tamamlanması amacılla ventralde penoskrotal bileşkeye " $Z$ plasti" uygulandi.

BULGULAR: Ortanca hasta yaşı 31 (20-67) idi. Hastaların kilolarına göre beş hasta normal kiloda, dokuz hasta aşırı kilolu, beş hasta ise obez iken, hiçbir hasta morbid obez değildi. Ortanca vücut kitle indeksi (VKI) ise $24,7(21,8-34,2) \mathrm{kg} / \mathrm{m} 2$ idi. Ortalama cerrahi süresi $65 \pm 25$ $\mathrm{dk}$ idi. Ortanca penis boyu uzaması $2,3(1,3-3,6) \mathrm{cm}$ idi $(\mathrm{p}<0,05)$. Dört hastada postoperatif yara yeri enfeksiyonu gelişti.

SONUÇ: Önerdiğimiz cerrahi insizyon tekniği, özellikle hafif-orta obez olan ve penis kısalığından yakınan hastalarda düşük komplikasyon oranları ile optimal estetik sonuçlar elde edilen ve peniste anlamlı uzunluk artışı sağlayan basit, güvenli ve etkili bir cerrahi yöntemdir.

Anahtar Kelimeler: gömük penis, obezite, penis boyu

\section{ABSTRACT}

OBJECTIVE: We present a novel suprapubic incision technique to obtain amore esthetical and longer penis appearance in adult patients with complaining buried penis.

MATERIAL AND METHODS: We retrospectively evaluated medical records of 19 patients who underwent reconstruction of adult buried penis in our clinic between 2013 and 2016. All procedures began with a $8 \mathrm{~cm}$ transvers downward crescent incision $2 \mathrm{~cm}$ above the penoscrotal junction. After removing all adipose tissue among skin, rectus fascia, and penile root (suprapubic lipectomy), the lateral tips of the incision are fixed in the midline from their subdermis to rectus fascia. Thus, the transvers incision is broughtto vertical plan. The tips of the new vertical incision are extracted like an open triangle to obtain a more esthetical wound suturation. After suturation, a ventral " $Z$ plasty" incision is applied to penoscrotal junction to prevent the dorsal growing penile length.

RESULTS: The median patient age was 31 (20-67). As regarding the weight of the patients, five had normal weight, nine patients were over weight, five patients were obese. None of the patients had morbide obesity. The median body mass index was $24.7(21.8-34.2) \mathrm{kg} / \mathrm{m} 2$. The mean operation time was $65 \pm 25 \mathrm{~min}$. The median increase in penile length was $2.3(1.3-3.6) \mathrm{cm}(\mathrm{p}<0.05)$. Postoperative wound infection occured in four patients (Clavien Grade 1).

CONCLUSION: The current incision technique is a simple, safe and successful procedure with minor complications, and obtains an acceptable and significant increase in penile length.

Keywords: buried penis, obesity, penile lenght
${ }^{1}$ Kocaeli Üniversitesi Tıp Fakültesi, Üroloji Anabilim Dalı, Kocaeli ${ }^{2}$ Derince Eğitim ve Araştırma Hastanesi, Üroloji Kliniği, Kocaeli

\section{Yazıșma Adresi/ Correspondence:}

Prof. Dr. Mustafa Melih Culha

Kocaeli Üniversitesi Lojmanları Tip5-8, Daire 5, Umuttepe, Kocaeli

41900 Kocaeli / Türkiye

Tel. $\quad$ +90532 2615431

E-mail: culhamm@hotmail.com

Geliş/Received: $\quad$ 18.03.2017

Kabul/Accepted: $\quad 29.03 .2017$

\section{GíRiș}

Gömük penis, normal korporal yapısı ile normal uzunluğu olan penisin suprapubik yağ içinde gizli kalmasına denir. Gömük penis, sıklıkla pediatrik yaş grubunda görülen bir durum olmasına rağmen, özellikle obezite ile ilişkili olarak erişkin yaşlarda da görülebilmektedir. Erişkin hastaların büyük çoğunluğu obez olsa da, kilo verilmesi ile, özellikle suprapubik pannus nedeniyle sorun devam etmektedir. ${ }^{[1]}$ 
Sünnet sonrası skar kontraksiyonu, masif skrotal lenfödem, balanitis xerotika obliterans ve liken sklerozus, erişkin kazanılmış gömük penisin diğer sebepleridir. ${ }^{[2]}$

Erişkin gömük penis olgularında hem fiziksel (seksüel disfonksiyon, işeme zorluğu, cilt irritasyonu, idrar yolu enfeksiyonu vb.) hem de psikolojik sorunlar tespit edilmiştir. ${ }^{[3]}$ Buna karşın, erişkin gömük penis tedavisinde temelde farklı etiyolojik durumlara yönelik çok sayıda cerrahi teknik tanımlanmış olsa $\mathrm{da}^{[2,4-7]}$ gömük penis tedavisi için genel kabul görmüş standart bir yaklaşım bulunmamaktadır.

Çalışmamızda, erişkin gömük penis hastalarında suprapubik lipektomi sonrası penisin daha uzun ve estetik görünmesi için uyguladığımız suprapubik insizyon tekniğini değerlendirmeyi amaçladık.

\section{GEREÇ Ve YÖNTEM}

Kliniğimizde 2013-2016 yılları arasında, suprapubik yağlanma nedeniyle fonksiyonel penis boyunun kısaldığını düşünen 19 hastanın verileri geriye dönük değerlendirildi. Diğer olgular (morbid obezite, sünnet sonrası skatris, skrotal lenfödem, liken sklerozus etiyolojili gömük penis hastaları) çalışma dışı bırakıldı. Demografik, klinik ve operatif verileri değerlendirildi ve analiz edildi. Penis boyu, flask haldeyken simfizis pubis ile penisin en uç noktası arasındaki gergin mesafe olarak ölçüldü.

İstatistiksel analizler "Statistical Package for the Social Sciences, version 21" programı ile yapıldı. Demografik verilerin analizi için tanımlayıcı istatistikler kullanıldı. Operasyon ile elde edilen penil uzamanın analizi için Mann-Whitney U testi kullanıld.

\section{Cerrahi teknik}

Hastalara, genel veya spinal anestezi altında supin pozisyonda cerrahi uygulandı. Hastaların hepsine perioperatif ve postoperatif antibiyotik profilaksisi uygulandı.

Penopubik bileşkenin yaklaşık $2 \mathrm{~cm}$ üstünden ters hilal şeklinde $8 \mathrm{~cm}$ 'lik transvers cilt insizyonu (Resim 1A)

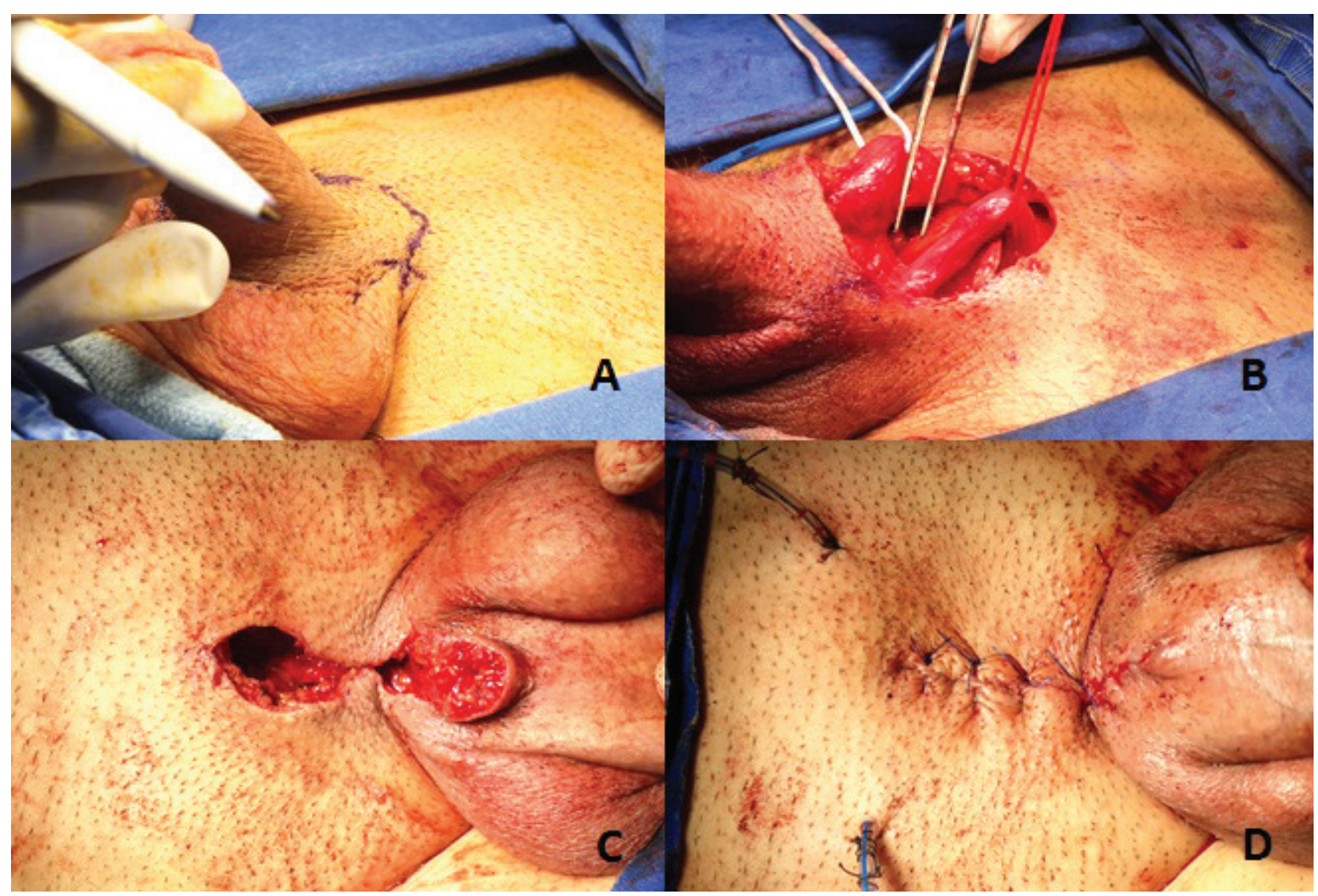

Resim 1. Suprapubik insizyon tekniği. A. Penopubik bileşkenin yaklaşık $2 \mathrm{~cm}$ üstünden ters yarım ay şeklinde açılmış $8 \mathrm{~cm}$ lik transvers cilt insizyonu. B. Suprapubik lipektomi sırasında her iki kordun zarar görmemesi ve disseksiyonun güvenli olması için askıya alınması. C. Transvers insizyonun lateral uçları subdermislerinden orta hatta rektus fasyasına iki adet sütür ile sabitlenerek insizyonun vertikal plana getirilmesi. D. Dren konulması, insizyonun kapatılmasından sonraki görünüşü. 
Tablo 1. Hasta karakteristikleri

\begin{tabular}{ll}
\hline Hasta sayısı, $n$ & 19 \\
\hline Yaş, ortanca (aralık) yıl & $31(20-67)$ \\
VKi, ortanca (aralık) kg/m² & $24,7(21,8-34,2)$ \\
Perioperatif komplikasyon, $\mathrm{n}$ & 0 \\
Preoperatif penis boyu, ortanca (aralık) cm & $8,1(6-11)$ \\
Postoperatif penis boyu, ortanca (aralık) cm & $10,4(7,2-14)$ \\
Peniste uzama, ortanca (aralık) cm & $2,3(1,3-3,6)^{* *}$ \\
Hastanede yatış, ortanca (aralık) gün & $3(2-5)$ \\
Postoperatif komplikasyon, $\mathrm{n}$ & 4 \\
\hline${ }^{*} \mathrm{ss}$, standart sapma &
\end{tabular}

yapıldıktan sonra penis kökü, rektus fasyası ve cilt arasındaki tüm adipoz dokular eksize edildi (suprapubik lipektomi). Bu sırada her iki kord, zarar görmemeleri ve disseksiyonun güvenli olması için askıya alındı (Resim 1B). Ardından insizyonun lateral uçları subdermislerinden orta hatta rektus fasyasına $2 / 0$ emilebilir poliglaktin sütürler ile sabitlendi (Resim 1C). Böylece, transvers insizyon vertikal plana getirilmiş oldu. Vertikal planda alt ve üst uçta oluşan cilt kulakçıkları açık üçgen şeklinde eksize edilerek, insizyonun estetik görünümünün sağlanması amaçlandı. Suprapubik lipektomi alanına her iki yandan birer adet negatif basınçlı diren yerleştirildi. Ardından, cilt altı $3 / 0$ monofilaman poligiton tek tek sütürler ile, cilt ise $2 / 0$ polipropilen sütür ile matris kapatıldı (Resim 1D).

Suprapubik lipektomi ile elde edilen penis uzunluğunun korunması ve tamamlanması amaciyla, ventralde penoskrotal bileşkeye "Z plasti" uygulandı.

\section{BULGULAR}

Ortanca hasta yaşı 31 (20-67) idi. Hastaların kilolarına göre beş hasta normal kiloda (VKİ 18,5-24,9), dokuz hasta aşırı kilolu (VKİ 25,0-29,9), beş hasta ise obez (VKI $>30,0)$ iken, hiçbir hasta morbid obez değildi. Ortanca vücut kitle indeksi (VKI) ise 24,7 $(21,8-34,2) \mathrm{kg} / \mathrm{m}^{2}$ idi (Tablo 1). Hastaların hepsinde gömük penis nedeniyle cinsel problem mevcutken, hiçbirinde ereksiyon problemi yoktu.

Ortalama cerrahi süresi $65 \pm 25 \mathrm{dk}$ idi. Hastaların hiçbirinde perioperatif komplikasyon izlenmedi. Ortanca penis boyu uzaması $2,3(1,3-3,6) \mathrm{cm}$ idi $(\mathrm{p}<0,05)$ (Tablo 1). Dört hastada yara yeri enfeksiyonu gelişti. Yeni bir girişime gerek kalmadan, uygun antibiyotik tedavisi ve tekrarlayan pansumanlarla tedavi edildi (Clavien Grade 1 komplikasyon).

\section{TARTIȘMA}

Erişkin gömük penis cerrahisinde tedavi hedefi, genitoüriner fonksiyonları en iyi kozmetik sonuçla geri kazanmaktır. Bu hastalarda, görünür penis boyu flask ve erekte haldeyken bile kısalmıştır ve bu durum psikolojik ve fizyolojik sorunlara neden olmaktadir.

Gömük penis, konjenital veya edinsel nedenlerden kaynaklanabilmektedir. Konjenital gömük penis, suprapubik yağ yastıkçıkları ve penisi karın içine doğru çeken kalın ve bozuk gelişimli dartos fasya bantları ile karakterizedir. ${ }^{[7,8]}$ Bunun yanında, yaygın cilt kaybına yol açan hatalı sünnet operasyonları da çocuklarda gömük penise neden olabilir. Erişkin gömük penis ise iki temel problemden kaynaklanır; suprapubik yağlanma ve skar oluşumu. Kilo alan erkeklerde suprapubik bölge, yağ birikimi için öncelikli alanlardandır. Üstelik, kilo kaybı ile buradaki yağ genellikle varlığını devam ettirir. ${ }^{[1]} \mathrm{Bu}$ nedenle, obezite hem erişkin gömük penisin en sık nedenlerindendir hem de var olan patolojiyi agreve eder. Buna eşlik eden diabetes mellitus da, bozulmuş hijyenli genital bölgede enfeksiyonları ve buna bağlı skar oluşumunu arttırır. Geçirilmiş operasyonlara bağlı veya idiyopatik genital lenfödem, travma, filariasise bağlı genital elefantiyazis ve liken sklerozus, erişkin gömük penis patofizyolojisinde diğer etiyolojik faktörlerdir. ${ }^{[0-13]}$

Erişkin gömük penis etiyolojisindeki bu farklılıklar, farklı cerrahi yaklaşımları ve farklı anatomik yapılara müdahaleleri gerektirir. Bu nedenle, literatürde erişkin gömük penis cerrahisi adı altında pek çok farklı teknik önerilmektedir. Westerman ve ark., \%87'si (13/15) biyopsi ile kanıtlanmış liken sklerozuslu hastaya, kendi tanımladıkları skrotal cilt flebi ile ventral kesi (VSSF) operasyonu uygulamıslar ve yaklaşık \%75 başarı elde etmişlerdir. Obez hastaları dahil ettikleri halde, gömük penise katkı sağlayan suprapubik adipozitesi olanları çalışma dışı bırakmışlardır. ${ }^{[4]}$ Yine aynı 
grup farklı çalışmalarında, yaklaşık \%40'ında morbid obezite ve \%34'ünde skrotal lenfödem olan hastalarına, kendi hazırladıkları sınıflandırmaya göre falloplasti, VSSF, çevre doku transferi, split thickness deri grefti gibi agresif yaklaşımlar uygulamışlar ve başarılı sonuçlarını yayımlamışlardır. ${ }^{[5]}$ Çalışmamıza, liken sklerozlu, morbid obez ve skrotal lenfödemli hasta alınmadı. Ghanem ve ark., \%60'ı (6/10) obez olan hastalarına, gömük penis nedeniyle sadece kendi liposuction tekniklerini uygulamışlar ve falloplastiye benzer penis uzama sağladıklarını öne sürmüşlerdir. ${ }^{[2]}$ Alter ve ark. ise, farklı etiyolojileri olan altı yetişkin hastaya, penoskrotal bileşke subdermisinin penil tunika albugineaya sabitlenmesi, suprapubik dermatolipektomi, parsiyel veya tam suspensor ligaman kesisi, penopubik subdermisin rektus fasyasına sabitlenmesi ve penoskrotal "Z plasti” operasyonları uygulamışlardır. ${ }^{[7]}$ Hastalarımızın hiçbirine, ereksiyon fizyolojisinin bozulmaması amacıyla, suspensor ligaman kesisi uygulanmadı. Figler ve ark. ise pannikülektomi yaptıkları hastalarını sunmuşlardır. ${ }^{[6]}$

Öne sürdüğümüz suprapubik insizyon tekniği ile, özellikle hafif-orta dereceli olgularda suprapubik lipektomi sonrası masif cilt eksizyonu yapmadan gergin bir penopubik cilt elde edilmekte ve ventralde oluşturulan "Z Plasti" ile önemli miktarda penil uzama sağlanmaktadır. İnsizyonun lateral uçlarındaki subdermisin orta hatta rektus fasyasına sabitlenmesi, penupubik yer değiştirmeyi engellemekte ve böylece elde edilen gerginliğin penil uzamaya yansıması sağlanmaktadır. İlk defa Horton ve ark., suprapubik alan yağdan arındırıldıktan sonra yapılan abdominoplasti ile herniye cildin rektus fasyasına sabitlenmesinin daha iyi sonuçlar verdiğini öne sürmüşlerdir. ${ }^{[14]}$ Benzer şekilde Adham ve ark., liposuction ve abdominoplasti sonrası herniye cildin ve penopubik bileşkenin rektus kılıfına sabitlenmesini önermişlerdir. ${ }^{[9]}$

Ghanem ve ark., $8,9 \mathrm{~cm}$ ve üzeri penis boyunu normal kabul etmişler ${ }^{[15]}$; başka bir çalışmalarında ise, penis boyunda elde edilen 1-2 cm'lik uzamanın başarı olduğunu ileri sürmüşlerdir. ${ }^{[16]}$ Bizim hastalarımızın ortalama penis boyu $8,1 \mathrm{~cm}$ ve belirtilen sınırların altında idi ve uyguladığımız cerrahi teknik ile ortalama $2,3 \mathrm{~cm}$ uzama sağladık.

Voznesensky ve ark., hastaların $\% 75$ 'inde (9/12) yara yeri komplikasyonlarının geliştiğini saptamışlardır. ${ }^{[3]}$ Erişkin gömük penis hastalarının çoğunlukla obez olması, sıklıkla diabetes mellitusun eşlik etmesi ve yaygın lipektomi yapılması, yara yeri komplikasyonları riskini arttırmaktadır. Çalışmamızın başlarında daha sık karşılaştığımız yara açılması ve enfeksiyon nedeniyle, sonrasında suprapubik bölgeye iki adet negatif basınçlı diren koymaya ve bunların getirisi 20 cc'nin altına düşmeden çekmemeye başladık.
Her ne kadar hastanede yatış süremiz uzasa da, sonrasında kontrolsüz diabetes mellitusu olan bir hasta dışında, yara yeri komplikasyonumuz olmadi.

\section{SONUÇ}

Sonuç olarak, önerdiğimiz cerrahi insizyon tekniği, özellikle hafif-orta obez olan ve penis kısalığından yakınan hastalarda, düşük komplikasyon oranları ile optimal estetik sonuçlar elde edilen ve peniste anlamlı uzunluk artışı sağlayan basit, güvenli ve etkili bir cerrahi yöntemdir.

\section{KAYNAKLAR}

1. Warren AG, Peled ZM, Borud LJ. Surgical correction of a buried penis focusing on the mons as an anatomic unit. J Plast Reconstr Aesthet Surg 2009;62:388-92. PubMed PMID:17684003. doi: 10.1016/j.bjps.2007.06.017

2. Ghanem H, ElKhaiat YI, Motawi AT, AbdelRahman IF. Infrapubic Liposuction for Penile Length Augmentation in Patients with Infrapubic Adiposities. Aesthetic Plast Surg 2017. PubMed PMID:28155063. doi: 10.1007/s00266-017-0786-2. [Epub ahead of print]

3. Voznesensky MA, Lawrence WT, Keith JN, Erickson BA. PatientReported Social, Psychological, and Urologic Outcomes After Adult Buried Penis Repair. Urology 2017. PubMed PMID:28132851. doi: 10.1016/j.urology.2016.12.043. [Epub ahead of print]

4. Westerman ME, Tausch TJ, Zhao LC, Siegel JA, Starke N, Klein AK, et al. Ventral Slit Scrotal Flap: A New Outpatient Surgical Option for Reconstruction of Adult Buried Penis Syndrome. Urology 2015;85:1501-4. PubMed PMID:25872692. doi: 10.1016/j.urology.2015.02.030

5. Tausch TJ, Tachibana I, Siegel JA, Hoxworth R, Scott JM, Morey AF. Classification System for Individualized Treatment of Adult Buried Penis Syndrome. Plast Reconstr Surg 2016;138:703-11. PubMed PMID:27152580. doi: 10.1097/PRS.0000000000002519

6. Figler BD, Chery L, Friedrich JB, Wessells H, Voelzke BB. Limited Panniculectomy for Adult Buried Penis Repair. Plast Reconstr Surg 2015;136:1090-2. PubMed PMID:26182174. doi: 10.1097/ PRS.0000000000001722

7. Alter GJ, Ehrlich RM. A new technique for correction of the hidden penis in children and adults. J Urol 1999;161:455-9. PubMed PMID:9915425.

8. Alter GJ, Horton CE, Horton CE Jr. Buried penis as a contraindication for circumcision. J Am Coll Surg 1994;178:48790. PubMed PMID:8167886.

9. Adham MN, Teimourian B, Mosca P. Buried penis release in adults with suction lipectomy and abdominoplasty. Plast Reconstr Surg 2000;106:840-4. PubMed PMID:11007398.

10. Chopra CW, Ayoub NT, Bromfield C, Witt PD. Surgical management of acquired (cicatricial) buried penis in an adult patient. Ann Plast Surg 2002;49:545-9. PubMed PMID:12439025. DOI: 10.1097/01.SAP.0000017984.37197.8F

11. Cromie WJ, Ritchey ML, Smith RC, Zagaja GP. Anatomical alignment for the correction of buried penis. J Urol 1998;160:14824. PubMed PMID:9751399.

12. Pestana IA, Greenfield JM, Walsh M, Donatucci CF, Erdmann D. Management of "buried" penis in adulthood: an overview. Plast Reconstr Surg 2009;124:1186-95. PubMed PMID:19935302. doi: 10.1097/PRS.0b013e3181b5a37f 
13. Alici B, Culha M, Ozkara H, Akkuş E, Hattat H. Management of buried penis in adults. Urol Int 1998;61:183-5. PubMed PMID:9933843. doi: 30320

14. Horton CE, Vorstman B, Teasley D, Winslow B. Hidden penis release: adjunctive suprapubic lipectomy. Ann Plast Surg 1987;19:131-4. PubMed PMID:3662345.

15. Ghanem H, Glina S, Assalian P, Buvat J. Position paper: Management of men complaining of a small penis despite an actually normal size. J Sex Med 2013;10:294-303. PubMed PMID:22512935. doi: 10.1111/j.1743-6109.2012.02725.x
16. Ghanem H, Shamloul R, Khodeir F, ElShafie H, Kaddah A, Ismail I. Structured management and counseling for patients with a complaint of a small penis. J Sex Med 2007;4:1322-7.PubMed PMID:17419818. doi: 10.1111/j.1743-6109.2007.00463.x 